\title{
Intercultural Awareness of Iranian English Language Learners: An Exploration
}

\author{
Zahra Edalati Kian \\ Department of Language and Communication Studies \\ University of Jyväskylä \\ Zahra.z.edalati-kian@jyu.fi
}

\section{Keywords:}

Intercultural awareness

Culture

Language learners

English as a Foreign Language

English as a lingua franca 
Abstract

The present paper reports on a qualitative study investigating how Iranian learners of English as a foreign language understand culture and the extent to which this understanding meets the needs of efficient intercultural communication. In order to gather data, in-depth semistructured interviews were conducted with eight participants. The interviews were designed and thematically analyzed using Baker's (2011) model of intercultural awareness. The model, which served as the analytical framework of the study, has been used to account for the knowledge, skills, and attitudes needed to communicate through English as a lingua franca. Based on the findings of the study, the main elements of the model are relevant in accounting for intercultural awareness-which varied among the participants-not only in English as a lingua franca setting but also in contexts where partners with different cultural backgrounds speak the same first language. Moreover, with the aim of developing learners' intercultural awareness, the policies and practices of English as a foreign language teaching in Iran need to be revised. 


\section{Introduction}

It looks like Americans are more honest. Europeans are imposters...it's like they are not honest with you, but people from the U.S. are really honest. These people are really simple. They are just themselves, they don't brag much. (Noora)

The quotation above is from a well-educated 31-year-old Iranian woman. Despite her definitive statements about Americans and Europeans, she has never been to Europe or the U.S.

The ability to move beyond cultural generalizations and stereotypes requires an awareness of the complexities of cultures, that is, an advanced cultural awareness (Baker, 2011). Culture has long been an element of language pedagogy, even in the Grammar-translation method, where the goal was to have access to the canons of Greek and Latin literature (Hermessi, 2016). However, it was not until a few decades ago that more attention was paid to intercultural communication-and culture in its own right-in language education. Despite the shift at the research and policy levels, this attention has only been on a superficial level; for instance, the essentialist and uncritical focus on national cultures (Baker, 2015). In the world of globalization and internationalization, language pedagogy "can no longer make do with focusing on the target language and target countries-and on cultures as territorially defined phenomena" (Risager, 2007, p. 1). Risager (2007) suggests that instead of a national paradigm, modern language studies should take on a transnational one that recognizes linguistic and cultural complexity.

Today, language education is based on an intercultural approach, with an ultimate goal of intercultural communicative competence rather than native speaker competence (Byram, 1997). However, this is the ideal. Whether or not this approach is followed in all contexts is the subject of debate.

English education in Iran consists of two divergent models: the indigenized or culturally/ideologically adapted English in the state-run public sector and the international Anglo-Americanized English in the private sector (Borjian, 2015). According to Borjian (2015), indigenized English-in which some aspects, such as phonology, morphology and syntax, are selectively accepted while some others, such as cultural elements, are totally eliminated-is the product of the indigenization movement that began after the Islamic revolution in 1979. Due to the prescribed syllabus and content, which mainly focus on reading skills, grammar, and vocabulary, after six years of formal English education in the public sector, learners usually have minimal communication skills (Sadeghi \& Richards, 2016). They do, however, have another option: private language institutes.

In accordance with the government's neoliberal economic policies, which favor the decentralization of state-run agencies, private language institutes have proliferated nationwide since the 1990s (Borjian, 2015). Unlike public schools, these institutes are allowed to have their own curricula and textbooks as long as they follow the government's broader laws (Borjian, 2015). Having no obligation to observe international copyright laws, they mainly use English language textbooks published by international publishing houses such as Oxford University Press. The failure of the public model to meet the learners' needs, the private section's rather liberal curriculum, and the fact that many of private institutes advertise themselves as representatives of foreign universities have all contributed to the popularity of private language institutes in Iran, especially among the 55\% of the population under the age of thirty (Borjian, 2015).

The present study is part of a bigger project examining the role of culture and intercultural competence in English as a foreign language education in Iran. In order to narrow down the scope of the research-which focuses on varying aspects, including textbooks, learners, and teachers-one specific private language school was chosen as the context. Safir Language Academy, which started its educational activities in 1999, is now the pioneer of English 
language education in the country, with more than 107 branches in Tehran and other provinces. The focus of this part of the project is on learners, in an attempt to answer the following question:

To what extent is Iranian English language learners' understanding of culture in line with the intercultural awareness needed to communicate through English as a lingua franca?

\section{Theoretical Framework}

\subsection{On the Concept of Culture}

The teaching of culture and intercultural competence depends on the needs and purposes of the learners on one hand and the educational priorities of the institutions on the other (Kramsch, 2013). According to Kramsch (2013), there are two main perspectives on culture in language pedagogy, depending on one's political orientation as well as whose interests are considered significant: modernist and postmodernist. The national paradigm in language education is based on the modernist view of culture, which has been challenged by the emergence of English as a lingua franca that has few if any national boundaries (Kramsch, 2013). Unlike the modernist view, in which culture is a set of established societal structures and national customs, the postmodernist-post-structuralist or ecological depending on the discipline-perspective characterizes culture as multiplicity, change, and power struggles (Kramsch, 2013).

Risager (2006) discusses the relationship between language and culture, providing a concise outline of the development of the concept of culture. She refers to some of the most important dimensions, categories, and definitions of culture provided by scholars in different disciplines, including two types of categorizations: the hierarchical, differential, and generic concepts of culture described by Zygmunt Bauman (1999) and the individual, collective, and aesthetic concepts of culture. Furthermore, Risager (2006) outlines the conceptions of culture, including the holistic concept of culture, cultural relativism, the cognitive concept of culture, the structuralist concept of culture, the interpretive concept of culture, and the practice-oriented concept of culture. Another comprehensive definition of the concept of culture was provided by Kroeber and Kluckhohn (1952):

Culture consists of patterns, explicit and implicit, of and for behavior acquired and transmitted by symbols, constituting the distinctive achievement of human groups, including their embodiments in artifacts; the essential core of culture consists of traditional (i.e., historically derived and selected) ideas and especially their attached values; culture systems may, on the one hand, be considered as products of action, on the other as conditioning elements of further action. (p. 357)

However, this was one of the last efforts to define culture in a way that would be applicable in all contexts. Since then, there has been a common understanding that it is impossible to give an authoritative definition of culture (Risager, 2006).

More recently, Baker (2015), in a thorough examination of culture through English as a lingua franca (ELF), gives an outline of different conceptions of culture, including culture as a product, culture as discourse, culture as practice, and culture as ideology. Considering the fact that there are multiple accounts of culture and no single definition of the concept on which there is consensus, it is not difficult to conclude that culture is complex. 


\subsection{ICA: A Model of Intercultural Awareness}

The analytical framework used in the present study was Baker's (2011) model of intercultural awareness. He offers this model to account for the knowledge, skills, and attitudes needed to communicate through ELF. According to Seidlhofer (2011), English as a lingua franca refers to "any use of English among speakers of different first languages for whom English is the communicative medium of choice, and often the only option" (p. 7). While building on previous attempts to conceptualize knowledge, skills and attitudes for successful intercultural communication, such as Byrams's (1997) model of intercultural communicative competence and specifically his concept of critical cultural awareness, as well as Risager's (2007) concept of "intercultural competence of the world citizen," Baker departs from them in that he emphasizes the complexities of global lingua franca contexts. Elaborating on the relationship between language and culture, he rejects the national paradigm suggested by previous scholars such as Byram and contends that a language such as English is no longer necessarily attributed to any particular community. Baker (2011) defines intercultural awareness (ICA) as:

a conscious understanding of the role culturally based forms, practices and frames of reference can have in intercultural communication, and an ability to put these conceptions into practice in a flexible and context specific manner in real time communication. (p. 202)

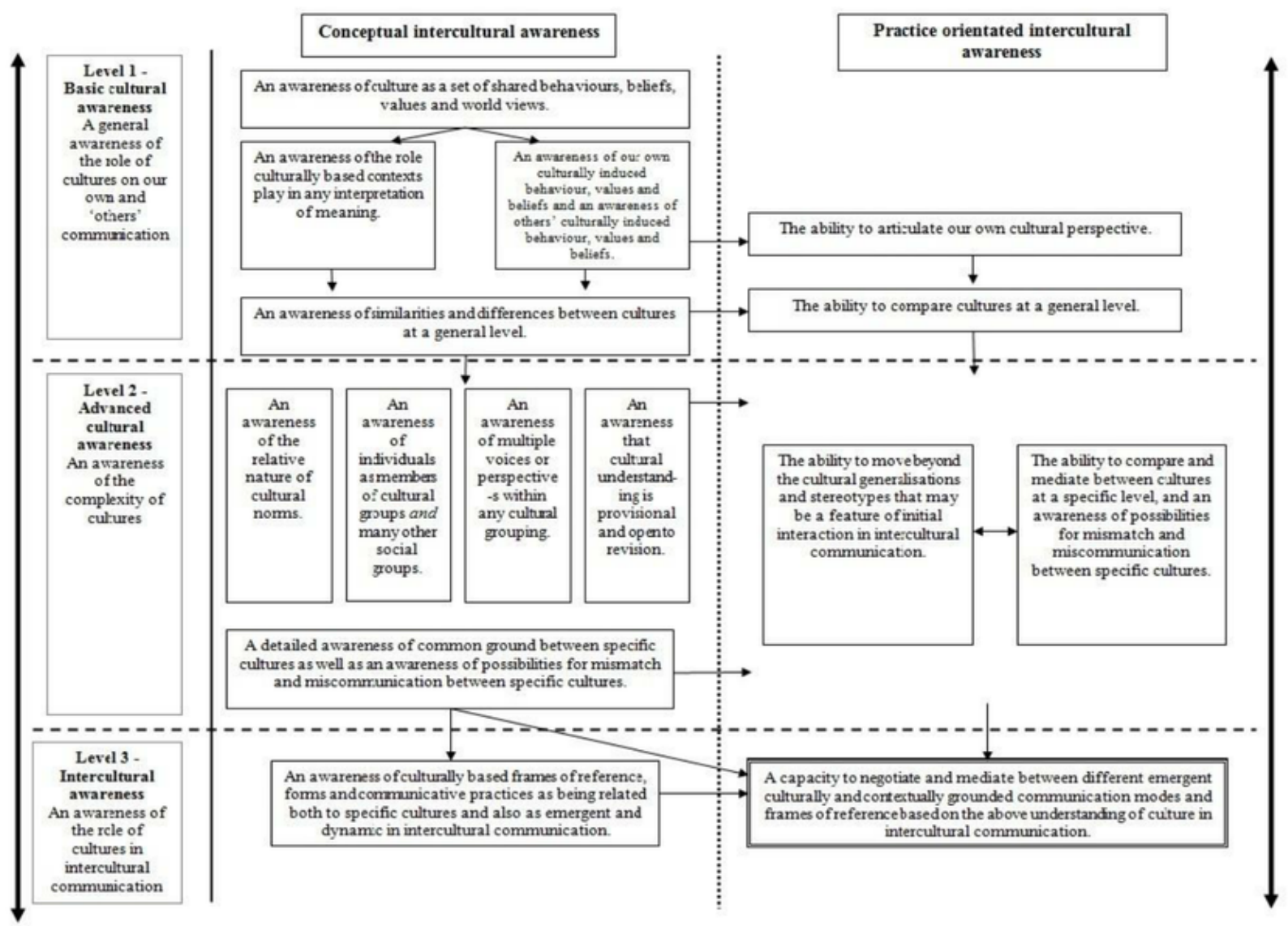

Figure 1. A model of intercultural awareness (Baker, 2011). 
As can be seen in Figure 1, ICA is composed of three levels: basic cultural awareness, advanced cultural awareness, and intercultural awareness. As stated by Baker (2015) himself, the first two levels are quite similar to Byram's (1997) saviors in his model of Intercultural Communicative Competence (ICC). Moreover, level 3 could also be comparable to Byram's notion of critical cultural awareness, specifically with regard to the role of mediation and negotiation. Nevertheless, it is here that ICA is distinguished from critical cultural awareness, as ICA emphasizes the fluid, complex, and emergent nature of culture and intercultural communication, where references that are drawn on in communication go far beyond national cultures. At this level, as described by Baker, the dichotomy of our culture vs. their culture, which is basic in Byram's (1997) ICC, is no longer relevant. However, ICA "involves an awareness of cultures, languages and communication which are not correlated and tied to any single native speaker community or even group of communities" (Baker, 2015, p. 166).

It is important to note that the model is not a developmental one, meaning that the development of ICA is not supposed to follow the order presented here. Moreover, Baker emphasizes that the distinctions made between different levels in the model are more conceptual than empirical in nature; hence the dashed lines. As shown by the multiple arrows, all kinds of awareness and abilities mentioned in the model are interrelated, and each level feeds into the other. To investigate the concept of ICA, four main categories of awareness and abilities can be drawn from the model. These themes are discussed briefly in the following.

\section{- One's own culture}

The first level of the model is about the basic awareness of what culture is, how it affects our values and behavior, and thus the role it has on the communication we have with others. Every one of us, as individuals, belongs to different cultural groups, such as the national group we identify with, our city, our family, our profession (artists, taxi drivers, doctors, etc.), our religion, and our ethnicity. The list could go on and on; however, this is only the surfacewhat others might see in us. The truth is more complicated. While technically being a member of these groups, a person might feel that he or she does not belong there. There might be discrepancies between what is generally attributed to some cultural groups and how the socalled members of those groups actually feel or behave. This awareness of multiple voices or perspectives within any cultural grouping comes at the second level of the model.

\section{- Complexity of cultures}

Awareness of the complexity of cultures comes at the second level of the ICA model. This entails a general understanding that there are similarities and differences between cultures, which could lead to common ground between specific cultures or cause mismatches and miscommunication between others. Here, the complexity of cultures refers to the dynamic, fluid, and relative nature of all cultural characterizations.

\section{- Cultural stereotypes}

There is no single definition of stereotypes upon which everyone agrees. However, most agree on its basic nature: stereotypes are "pictures in our heads" of other groups (Lippman, 2017). A stereotype could be defined as "a widely held but fixed and oversimplified image or idea of a particular type of person or thing" (Stereotype, n.d.). Baker (2011) mentions the issue of cultural stereotypes in the second level of his ICA model, advanced cultural awareness, highlighting "the ability to move beyond the cultural generalizations and stereotypes that may be a feature of initial interaction in intercultural communication." Considering the phrase above, it could be concluded that having cultural stereotypes is a negative thing; however, Baker does not discuss how complicated this issue actually is. Even the definition of cultural stereotypes is taken for granted. 
- Negotiation and mediation between cultures

In his research on ICA, Baker (2011) suggests that negotiation and mediation are key elements in successful communication. He further explains that "negotiation here is not just negotiation of linguistic forms and meaning but also negotiation in relation to social identities and cultural frames of references and practices" (Baker, 2015, p.41). The concepts of negotiation and mediation are also central according to Hua (2014), who contends that "the field of intercultural communication is primarily concerned with how individuals, in order to achieve their communication goals, negotiate cultural or linguistic differences which may be perceived relevant by at least one party in the interaction" (p. 200). In the model of ICA (Baker, 2011), this comes at the third level as "a capacity to negotiate and mediate between emergent culturally and contextually grounded communication modes and frames of references based on the above understanding of culture in intercultural communication."

\section{Methodology}

In the present study, the methodology is qualitative in nature. In order to answer the research question, in-depth semi-structured interviews were conducted with eight Iranian learners of English. If the interest of the research is in what Schutz (1967, cited in Seidman, 2006) calls the participants' subjective understanding, then interviewing is usually the best method of inquiry (Seidman, 2006). Compared to questionnaires, interviews offer more flexibility and allow room for more spontaneity on the part of the respondents. Moreover, the power of language and storytelling makes interviewing a particularly powerful tool. As Vygotsky (2012) observes, "a word is a microcosm of human consciousness" (p. 271).

\subsection{Participants}

Robinson's (2014) theoretical and practical guide was used for sampling the participants. First, a sample universe or target population was defined using two inclusion criteria: being Iranian and having studied English for at least six months in a specific private language institute in Iran. Second, considering theoretical and practical issues, a sample size range was chosen with a minimum of six and a maximum of ten participants. In the next step, convenience sampling was chosen as the strategic method for selecting the cases. Convenience sampling "proceeds by way of locating any convenient cases who meet the required criteria and then selecting those who respond on a first-come-first-served basis until the sample size quotient is full" (Robinson, 2014, p. 32). Finally, the sample was sourced using online advertising as well as snowball sampling or referral chains, which involves asking participants to suggest others who qualify for participation.

The participants included two males and six females between the ages of 21 and 31 . They had all studied English-or were still studying at the time of the interview-in a specific private language institute in Iran. The amount of time they had studied there varied among the participants from six months to two years, sometimes with intervals, but the institute was not the only source for them to study/learn English. All the participants had access to different sources of English, including music, movies, social networks, books, and the Internet. However, they varied greatly regarding how much they used the mentioned sources and how much experience they had using ELF.

All the participants were informed about the use and purposes of the study as well as the voluntary nature of participation and what it would entail. Their anonymity was established through the use of pseudonyms, and they were allowed to ask questions and were provided with any information they needed before they verbally provided informed consent to participant in the study.

More information about the participants is provided in the appendix. 


\subsection{Interviews}

The aim of the interviews was to encourage the participants to talk about the four main themes drawn from Baker's (2011) model based on their own feelings and experiences. For this purpose, a set of questions was designed by the researcher and reviewed by some colleagues. This first draft of questions was then tested in a pilot interview, based on which the final version of the questions was prepared. However, the interviews with different participants varied greatly due to their different experiences and the topics and discussions that followed accordingly.

The interviews were conducted in the spring and summer of 2016. They were all done online, using the video/audio conversation applications Skype and WhatsApp. Five interviews were video conversations, and three were audio conversations. All of the interviews were audiorecorded for analysis purposes. The language of the interviews was Persian, the interviewees' mother tongue. Each interview took from 30 to 90 minutes, depending on the interviewees' willingness to share their thoughts and experiences. To facilitate analysis, the researcher transcribed all of the interviews verbatim.

\subsection{Analytical method}

As mentioned previously, the analytical framework used in the present study was Baker's model of ICA. For designing the interview questions, four main themes were drawn from the model, which were considered to have captured the essence of ICA. Following a top-down approach, the same themes were then used to analyze the data deductively. More specifically, the transcription of each interview was studied several times to find any representation of the four themes.

\section{Findings}

The present study was an attempt to answer the following question: To what extent is Iranian English language learners' understanding of culture in line with the intercultural awareness needed to communicate through English as a lingua franca?

In this section, the findings of the study are presented in light of each of the four themes drawn from Baker's (2011) model of ICA; namely, one's own culture, the complexity of cultures, cultural stereotypes, and negotiation and mediation between cultures. General findings within each thematic category are presented first, followed by detailed findings with illustrative extracts from different interviews. The extracts of the interviews used in the present article were translated into English by the researcher.

\subsection{One's Own Culture}

In general, all the participants have an awareness of their own culture and whether their cultural understanding is attributed to the different cultural groupings to which they belong. In addition, all of them mentioned that their cultural understanding has changed in some ways over time. Moreover, they are aware of the influence that their culture has on their communication with others.

Noora, a 31-year-old female, talks about her feeling that Iranians are all becoming similar and imitating each other. This is something she does not like it, and she prefers "to be herself": 
I just know that I have lots of problems with our own culture. I don't like anything traditional of our country [...] I thinks it's all rubbish [...] I don't know...many things are nonsense to me. I don't get it...but I find myself getting along with them out of respect...I feel like I don't belong to this culture.

The last sentence from the above quotation says a lot-the fact that she is officially Iranian but does not feel like one. This leads to an important question: What exactly is this culture that she does not feel that she belongs to? When asked this question, she says it is the Iranian culture. It is interesting that she believes in the existence of a national culture but does not identify with it.

In the next extract, Essi (22-year-old male) talks about his cultural differences with his family:

My parents are rather religious and traditional, especially my dad...it's like we [he and his brothers] say what we believe, but not loudly [laughs]...I mean we live our own lives...I know from my experience that in the family I should not always say what I believe, and it's better to keep distant and go my own way.

This contradicts the assumption that all members of a family have the same culture. Individuals can have their own culture, different from that of other members of the same family. This is also true in large contexts such as a city or country, highlighting the significance of cultural overgeneralizations and stereotypes.

Essi then continues to explain why he has decided to leave Iran in search of a better life. His main reason is the cultural ambiance in Iran. He believes that not everything (e.g., the fact that some people are sexist) is directly related to the government. He says that people have accepted sexism and laugh at it:

To be honest, many people say when they leave Iran and live in another country that they feel ghorbat [the feeling that they don't belong], but that's how I feel here, to some extent.

The feeling that he talks about-ghorbat in Persian-has no exact equivalent in English, but it translates roughly as "the state or feeling of being a foreigner and/or longing for one's native land" (Ghorbat, 2018). It was very interesting that in his own country, where he is supposed to feel a sense of belonging, he instead feels alienated. This shows that he knows his own culture and how it differs from other cultures. Additionally, he was able to articulate his own cultural perspective, an ability that Baker (2011) refers to in the first level of his model as basic cultural awareness.

In the next extract, Saara (21-year-old female) talks about her feelings of being a Kurdish Iranian. She says that in the past she was proud of being a Kurd:

Being an Iranian...I don't know [laughing] actually if I'm proud of that too or not...mmm, but [pause] I am proud of that too but to a lesser extent...I don't know. I wasn't like this before. You could say it was completely the opposite perhaps three or four years ago. I was much more proud of being an Iranian [than being a Kurd], and if some friend of mine emphasized being a Kurd, I'd say they are dogmatic and such, but now it's changed for myself. I don't know why [laughs] now I've also become like that, to some extent...Now I have the same feelings, but not to the extent of being a separatist and such...but...I don't have the same feeling of being an Iranian; maybe because I've met many people from all cities, and then somehow my view of the whole country changed...I think that's the reason.

For many people, their nationality and ethnicity are essential parts of their culture and of who they are. The interesting point in this case is how her thoughts and feelings regarding these two matters have changed over time and how fully aware of these changes she seems to be. 
As Baker (2011) puts it, she is aware that cultural understanding is provisional and open to change. Knowing how our own culture changes over time could positively affect our tolerance towards others with whom we might have divergence, hence improving our ICA.

\subsection{Complexity of Cultures}

The participants had learned about different cultures and their complexities in different ways and from different sources, including but not limited to English language textbooks, movies, TV shows, music, books, travel, social media, and interactions with foreigners. The participants differed in their level of knowledge about specific cultures and in their awareness of the complexities of cultures. Their willingness to learn more about such matters varied as well. Moreover, some of the participants showed deep awareness of the complexities of culture in one aspect or case but not in others.

In the extract below, Frans (28-year-old male) talks about his encounter with his family's CouchSurfing guests:

When you have a foreigner as a guest, first you get to know a completely different culture...maybe not completely different but very different. This is really interesting...for example, we were shocked the first few times when we'd get back home...we had planned to hang out with the guests...we'd ask if they are tired and wanted to rest. They'd say, "yes, we want to sleep," and we would be shocked, like, why did they say such a thing? Then, we understood that this is their lifestyle and culture and they don't have târof with other people. And, if you look into it, you realize that many times one happens to be in a situation where maybe it's better not to follow such formalities.

The reason they were shocked from this simple honest answer is that many Iranians tend to say yes on such occasions just to please their host (the concept of târof in Persian); otherwise, they might seem rude. There is no exact equivalent of this concept in English. However, it is very common among Iranians, especially in people with whom you are not very close or intimate. Its actualization in conversations might be in the form of "'ostensible' invitations, repeated rejection of offers, insisting on making offers, hesitation in making requests, giving frequent compliments, hesitation in making complaints, etc." (Sharifian, 2011, p. 143). In other words, a person might say or do things that he or she does not actually believe just to be polite. However, being polite or impolite could have different meanings in different cultures. It is interesting that Frans gradually learned that their guests were just different from them, with a different culture. Not only that, he also he seemed to like their way better, meaning he had learned something new. This is what Baker (2011) refers to as an awareness of the role culturally based contexts play in any interpretation of meaning.

In another case, Sanni (26-year-old female), another CouchSurfing host, talks about what she learned indirectly from one of her family's CouchSurfers:

He was French, and he only had a very small backpack. It was very strange...well we had already had many guests, and they all had two or three backpacks, but this one had only a small one.

Sanni continues, describing a time when she and the above-mentioned guest were standing in line together to vote for the presidential elections, and a French man was standing in front of her in the queue:

He was wearing baggy pants, and I saw that his pants were torn, like the size of a palm, at the back...it seemed weird to me...and there was a bunch of people behind us in the line...and it just came to my mind to wonder how much does a pair of pants cost...even here in Iran, he could buy one for like 30 thousand Toomans, which is 
nothing for him...but then I thought to myself, told myself, that it's your dream to be in his situation [laughs] countries he has visited...things he has done, experiences he has had... I didn't have even $1 \%$ of them...well there was another similar guest too...they don't care about clothes that much.

For Sanni, wearing such clothes seemed a little embarrassing at first. However, just a little bit of thinking helped her realize that it is something probably should not worry about. Sanni came to realize that clothes, which might seem to be a trivial issue and irrelevant to culture, could have different significance for different people. That is what Baker (2011) refers to as the relative nature of cultural norms, an awareness of which comes at the second level of his model: advanced cultural awareness.

\subsection{Cultural Stereotypes}

All the participants in the present study, at some point in their talks, demonstrated cultural stereotypes, most of them formed based on people's nationality or the city they come from in Iran. Many of the participants had learned about different cultures through their English textbooks, all of which were from large publishers (e.g., Oxford University Press) and thus internationally used. However, in many cases, the cultural references in the textbooks were so brief and shallow that they could actually trigger cultural stereotypes. As Ghadiri et al. (2014) points out, educators have to make an attempt to uproot the stereotypes in language textbooks.

Having gained an awareness of the complexities of cultures, some of the participants in this study seemed to have moved beyond cultural stereotypes and overgeneralizations in some cases but not in others. In addition, some of the participants seemed more comfortable holding positive rather than negative stereotypes. In the following extract, Jenni (30-yearold female) talks encountering people on her trips to different parts of Iran:

I have been to different parts of Iran. Each has a different culture, in general, compared to Tehran [where she lives]...in many of them, this cultural difference is shown mostly with regard to religion...many of them are different in their behaviors...for instance, people in the south of Iran were truly another kind...they were very warmhearted, and they would easily accept you among themselves and would comfortably talk to you...of course, you can find such people in Tehran as well, but they were truly warmhearted...but in Ardabil, for instance, people were different...when you walked on the streets, it seemed that people were aggressive; however, when you talked to them, you would realize that they were not actually like that, it's just their the way they behave; for example, their voices are loud.

In Jenni's words, there is a cultural stereotype about the people from the south of Iran that is actually collective (meaning that it is shared by many people). A crucial question arises: If cultural stereotypes are bad, are positive ones also bad, or should only negative ones be avoided? Jenni seems comfortable with the comment she made about the people from the south of Iran, possibly because there was nothing negative or offensive about it from her point of view. However, when she talks about people in Ardabil looking aggressive, she says that it might have been due to their loud voices, and maybe they are not actually like that. It is interesting that she elaborates on her first impression, which turned out to be wrong later. As Baker puts it, she moved beyond cultural stereotypes, which might be a characteristic of first encounters in intercultural communication.

In the next extract, Frans talks about some of the things he learned about different cultures through watching TV series: 
Among series, I mainly watch South Park, the animated series, through which I got to know different personalities from around the world...and culturally speaking, there was this American culture, which I think was well portrayed...I have talked to my friends who live or study in the US, and most of them also confirm that American people are actually like that...a bunch of impulsive people, who are overly involved with eating and such...I mean, these things happen a lot in their society.

When we talk to people, there are often some cultural stereotypes in their words, such as what Frans says about American people. However, if deeply investigated, these expressions might simply represent a lack of political correctness, linguistically speaking. Political correctness is used to refer to "language that seems intended to give the least amount of offense, especially when describing groups identified by external markers such as race, gender, culture, or sexual orientation" (Political correctness, n.d.). In the extract above, Frans makes a strong statement about Americans first, but then, in the next sentence, he moderates this by saying, "these things happen a lot in their society." The same could be true in many other conversations; that is, not everybody knows how to speak in a politically correct way. This is why caution should be exercised when calling people racist or sexist based on one or two sentences. However, the opposite is also true: Some people might know very well how to hide their questionable beliefs within politically correct words.

Here, Noora, talks about what she learned from the textbooks she used:

...for instance, Japanese eating culture, like in what way they eat food, and what is considered disrespect for them...or for instance if you are in Algeria, or I don't know, another Arabic country...if you see your friend in the taxi, you should pretend that you haven't seen them because otherwise, when you are getting off the taxi, you have to pay for them too. That's why people pretend that they don't know each other in a taxi; it's their culture.

Both examples mentioned above could be very interesting and informative cases of different cultures-if and only if they are approached mindfully. They should not lead to the belief that the traditions they refer to are permanently fixed, firmly established, and true of all the people from those countries. Teachers could play a crucial role in combatting such universal stereotypes, but the learners themselves could also use such information in a positive way, expanding their views of cultural complexities and preventing possible cultural stereotypes.

In the following extract, Hanna (29-year-old female) talks about how travelling to Russia made her realize how different people are from what she originally believed:

As for Russia, I strongly believed that Russians were cold-tempered and no one would respect me there...I mean, a bunch of tall, blond people in great shape who would not even look at me or care about me, but I was wrong. People were so kind.

The fact that she realized her presuppositions were wrong is very significant. This happened in so many cases with different people that she said she no longer trusts any sources other than what she sees with her own eyes. When asked if reading books had helped her get to know other cultures, she said:

Most books that we read are translations...they give me an idea, but honestly, after the contradictions that I found between what I thought and what I saw, I can't trust them like I did before. I mean, I prefer to see everything with my own eyes in order to decide about people [...] after so many mistakes that I made, I don't want to trust that anymore.

Although we can argue that face-to-face encounters are not only way to learn about other cultures, as Hanna claimed, the skeptical view one develops over time could actually 
contribute to ICA. Hanna now realizes that cultures are more complicated than what she hears or reads about them. Moreover, this critical view could help her postpone her judgment about other people from different cultures. However, there are adverse effects as well. She now has so much confidence in her own eyes that she overgeneralizes all the people from the same country. She had a chance to spend time with two individuals from France, and they were her only source of cultural information:

[The French] have easily omitted television from their lives. They care about what they eat, and they like to eat tasty food...They are different from us...I mean...for instance, if we go shopping, things that she buys are very different from what I choose.

Although she understands the differences between her own culture and that of her French friend, she makes the mistake of seeing her as representative of the whole country of France. She fails to realize that such cultural differences between the French friend and herself might also exist among French people themselves, and not all of them are the same.

In the next extract, she talks about the difference between men and women when it comes to discussions and debates:

Well, as for the people I know...I cannot say for $100 \%$, women are more...how can I say...they are easier [to talk to]...I mean, they are more flexible, and they listen to you...but well...this is my opinion.

Unlike her previous comments about different nationalities, here Hanna seems quite cautious not to make any stereotypical overgeneralizations. She emphasizes that this is true only about the people she knows, and she cannot say it about all women. Using Baker's (2011) words, in this case she seems to be aware of the fact that there are multiple voices or perspectives within any cultural grouping.

\subsection{Negotiation and Mediation between Cultures}

In the present study, the focus was on the participants' negotiation and mediation skills at a cultural rather than a linguistic level. This could apply to individuals who speak the same first language but have cultural differences. This theme was the least represented in the data. Only four of the participants elaborated on specific cases in which they had negotiated cultural differences with others.

In the following extract, Leila (23-year-old female), who has some religious and cultural differences with her mother, talks about an occasion when she tried to have a conversation with her mother about homosexuals (homosexuality is unacceptable both religiously and legally in Iran):

We were watching a documentary on BBC Persian about homosexuals and transsexuals...how they had to take asylum in Turkey or Canada, and most of them committed suicide in the end...My mom was saying that homosexuals are sick, but my sister and I said that it is just a sexual orientation, just like you prefer to be with your opposite sex...I guess she accepted...she doesn't say anything bad about them anymore.

According to some of the participants, negotiating cultural differences sometimes occurred in the languages courses in the time dedicated for discussion. For instance, Essi mentions topics such as gender segregation in schools and sex work:

The question was: what is the worst profession? ...and then the issue of sex work came up...some had the idea that a sex worker is just horrible...one student said that he/she had a friend who was a sex worker[...] and that she was just human like them. 
Although Essi is not the one who is negotiating a cultural issue, this is an interesting example that occurred in a language classroom setting. In the next extract, he is the one who takes the role of a mediator, negotiating a cultural issue with his mother:

We were at the airport, and I was looking in a different direction when my mom said, why is she [a random woman] dressed like that?...I asked, what is the problem? She said, what's that supposed to mean when someone is dressed like that?...I replied she must like it this way, and perhaps she thinks she looks better this way...My mom then said it can't be like that...there are certain rules in the country...I told her that in my opinion it is a personal choice how someone likes to dress or how they prefer to be seen...you could easily look in some other direction if it bothers you to see something, just like me, I was looking at something else.

The willingness to negotiate between cultures is not always the same among people. For his part, Essi seemed to be passionate about it. Here, Essi responds to a question about whether he believes that such discussions are useful:

Yes, in a number of ways...first, you get to learn about different thoughts, and I like that...to see different people, different opinions...perhaps someone's opinion is better than mine, so I'd learn to change mine...or perhaps I get to change someone else's mind...or maybe neither could happen, but it's not bad to get to know others' thoughts.

These attitudes of openness, curiosity, and discovery (ambiguity tolerance) are fundamental to intercultural competence (Deardorff, 2006).

Hanna also gave an example of her talking to her mother about homosexuality, taking the role of a mediator, because she thought her mother came from a different culture when it comes to this issue:

About homosexuality in our culture...for instance my mom had not noticed that it is something normal...usually when something is normal in other places of the world, it takes 20 or 30 years to become normal here...but it is, and you have to know that...and you should not think that they are sick, or I don't know...have such ideas...I had seen some people in my parents' age think so, so I thought my parents had better know that it is not the case.

She also mentions a conversation she had with a foreign guest who was curious about hijab, which is obligatory for Iranian women in public:

They had questions specifically about the issue of hijab...well they have complicated questions in their minds as to why basically...for instance, one of the interesting questions they asked me was how we swim in the sea...I said that we have separate times for men and women...he/she asked how far it is separate, like, how far away can you swim and still be separate from men?...and even I didn't know the answer, so I said I don't know...perhaps from one point further, it's your prize, and you get to swim with men, because I had never thought about it.

According to the law in Iran, women have to cover their bodies and hair in public. In the example above, Hanna negotiates this cultural issue and what entails with someone who had little understanding of it.

In another example, Sanni talks about a misunderstanding with one of their CouchSurfing guests from Estonia:

There was this very thin boy who was in love with Iranian food, and he ate...he ate a lot and loved it...I mean, he would say I'm full, but I have to eat more...once he was eating and he said that he's sorry he's eating like that...and I said in Iran everyone will 
love you when you eat like that because Iranians like to make food and their guests eat...but then he suddenly started to apologize and said that he's sorry, but he thought he could eat more...but then we explained to him that he doesn't have to worry and it's actually a good thing [laughs].

What Sanni did here is an interesting example of the negotiation of meaning and of different cultural norms in an emergent culturally grounded communication. There might have been linguistic negotiation as well, but the details of their conversation in English are not known.

\section{Discussion}

As stated in the previous sections, the model of ICA (Baker, 2011) used in the present study has been offered to conceptualize the intercultural competence needed to communicate in an ELF setting. Based on the findings of the study, the main concepts of ICA are all relevant to the types of knowledge and skills necessary for meaningful intercultural communication. The findings highlight a number of other points as well.

First, as shown by the illustrative quotes above, the main concepts are tightly interrelated, with no clear boundaries between them. For example, having an awareness of one's own culture entails an understanding of culture in general, its complexities, and how it influences communication with others, which in turn could help one move beyond cultural stereotypes. Second, the findings clearly show that it is possible to have an awareness/skill at an advanced level of the model while lacking another at the basic level. This indicates that the development of ICA does not necessarily proceed in the order of the levels presented in the model. Moreover, one might have an awareness/skill in one case but lack it in another, highlighting the indefiniteness and complexity of ICA. Finally, as demonstrated through some of the extracts above, although ICA is specifically designed to account for intercultural communication in ELF, it could have wider applications in settings in which partners, while speaking the same language, have different cultures.

\section{Conclusion}

The aim of the present study was to investigate how learners of English as a foreign language in Iran understand culture, and the extent to which this understanding supports meaningful intercultural communication in an ELF setting. The terms English as a foreign language (EFL) and English as a lingua franca (ELF) are "on opposite sides of the same coin": the English that is taught to or learned by non-native speakers (EFL), and the English that non-native speakers use in international communication (ELF) (Swan, 2012). According to Swan (2012), "the more we learn about efficient lingua franca communication in English, the better able we are to make informed decisions about priorities: what do we need to teach and what can we safely ignore?" (p. 388). In this sense, the findings of this study have implications for both fields.

The participants had access to various sources for learning about different cultures as well as the complexities of cultures in general; however, not all of these sources were equally useful for them. Most of what they had learned was outside the classroom context, through selfstudy and personal experiences. Moreover, the language textbooks, which fail to underscore the complexities of cultures, had created or reinforced cultural stereotypes, mainly on the national level. This calls for a purposeful revision of EFL education in Iran, directed towards the needs of ELF communication at both the policy and practice levels and involving material design and curriculum development as well as teacher education.

Moreover, the findings reveal that cultural stereotypes are the most prevalent issue in ICA. As stated earlier, although such stereotypes are present in Baker's (2011) model of ICA, their different aspects and complications are largely underestimated. Therefore, more research on cultural stereotypes in an ELF setting seems necessary. The outcome of such research could in turn help to reform EFL language planning. 


\section{Conflict of interest}

There is no personal, commercial, political, academic, or financial conflict of interest to disclose. 


\section{References}

Baker, W. (2011). Intercultural awareness: Modelling an understanding of cultures in intercultural communication through English as a lingua franca. Language and Intercultural Communication, 11(3), 197-214. Retrieved from https://doi.org/10.1080/14708477.2011.577779

Baker, W. (2015). Culture and identity through English as a lingua franca: Rethinking concepts and goals in intercultural communication (Vol. 8). Berlin: De Gruyter Mouton. https://doi.org/10.1515/9781501502149

Bauman, Z. (1999). Culture as praxis. Sage. (Work originally published 1973)

Byram, M. (1997). Teaching and assessing intercultural communicative competence. Clevedon: Multilingual Matters.

Borjian, M. (2015). Bridge or wall? English language in Iran. In N. Wadham-Smith \& D. Whitehead (Eds), New perspectives on UK-Iran cultural relations (pp. 201-223). London: British Council.

Deardorff, D. K. (2006). Identification and assessment of intercultural competence as a student outcome of internationalization. Journal of Studies in International Education, 10(3), 241-266. Retrieved from https://doi.org/10.1177/1028315306287002

Ghadiri, M., Tavakoli, M., \& Ketabi, S. (2015). Introducing culturally-adaptive English language pedagogy (CELP): Integrating critical cultural awareness through the 'little-c' culture in Iran's EFL curriculum. International Journal of Society, Culture and Language, $3(2), 115-124$.

Ghorbat (2018). In Wiktionary. Retrieved from https://en.wiktionary.org/wiki/\%D8\%BA\%D8\%B1\%D8\%A8\%D8\%AA\#Persian

Hermessi, T. (2016). Teacher cognition on the place of culture in English education in Tunisia. International Journal of Society, Culture \& Language, 4(2), 105-118.

Hua, Z. (2014). Exploring intercultural communication: Language in Action. London: Routledge.

Kramsch, C. (2013). Teaching culture and intercultural competence. In C. A. Chapelle. (Ed.), The encyclopedia of applied linguistics. Blackwell Publishing Ltd. Retrieved from https://doi.org/10.1002/9781405198431.wbeal1153

Kroeber, A. L., \& Kluckhohn, C. (1952). Culture - A critical review of concepts and definitions. New York: Vintage Books.

Lippmann, W. (2017). Public opinion. New York: Routledge. https://doi.org/10.4324/9781315127736

Political correctness (n.d.). In Encyclopedia Britannica. Retrieved from https://www.britannica.com/topic/political-correctness

Risager, K. (2006). Language and culture: Global flows and local complexity. Clevedon: Multilingual matters. https://doi.org/10.21832/9781853598609

Risager, K. (2007). Language and culture pedagogy: From a national to a transnational paradigm (Vol. 14). Clevedon: Multilingual Matters. https://doi.org/10.21832/9781853599613

Robinson, O. C. (2014). Sampling in interview-based qualitative research: $A$ theoretical and practical guide. Qualitative Research in Psychology, 11(1), 25-41. Retrieved from https://doi.org/10.1080/14780887.2013.801543

Sadeghi, K., \& Richards, J. C. (2016). The idea of English in Iran: An example from Urmia. Journal of Multilingual and Multicultural Development, 37(4), 419-434. Retrieved from https://doi.org/10.1080/01434632.2015.1080714

Seidlhofer, B. (2011). Understanding English as a lingua franca. Oxford: Oxford University Press.

Seidman, I. (2006). Interviewing as qualitative research: A guide for researchers in education and the social Sciences. New York: Teachers College Press. 
Sharifian, F. (2011). Cultural conceptualisations and language: Theoretical framework and applications (Vol. 1). Amsterdam/Philadelphia: John Benjamins Publishing. https://doi.org/10.1075/clscc.1

Stereotype (n.d.). In Oxford living dictionaries. Retrieved from https://en.oxforddictionaries.com/definition/stereotype

Swan, M. (2012). ELF and EFL: are they really different?. Journal of English as a Lingua Franca 1(2), 379-389. https://doi.org/10.1515/jelf-2012-0025

Vygotsky, L. S. (2012). Thought and language. (Revised and expanded ed.) Cambridge, MA: MIT press. (Original work published 1934) 


\section{Appendix}

Participants' backgrounds related to learning and using English

Essi (male) was 22 years old. He had been studying English at the institute for almost 15 months. Before that, he had been self-studying English using films and music and similar media. He had had few interactions in English and never travelled outside of Iran.

Frans (male) was 28 years old. He had studied English at the institute for eight months, which ended four months before the interview. He started watching movies and shows in English when he was 17 and focused on doing so for about four years. He had recently travelled to Turkey two times, and he had been a host for CouchSurfers for more than a year.

Sanni (female) was 26 years old. She started studying English at the institute four years ago. First, she took courses for a year, and after a one-year interval, she took some additional courses for another two years. Before that, since childhood, she had been going to other language institutes for short periods intermittently. She had recently travelled to Turkey two times, and she had been a host for CouchSurfers for more than a year.

Noora (female) was 31 years old. She had studied English at the institute for two or three years intermittently but stopped about two years ago. Before and after that, she had been self-studying. She had travelled to Turkey, Saudi Arabia, and India. Moreover, she had experienced several intercultural interactions in English in Iran and online.

Jenni (female) was 30 years old. She had studied English at the institute for a year about four years ago, and at the time of the interview, she had been taking courses again for about seven months. She had not travelled outside of Iran and had few interactions in English.

Saara (female) was 21 years old. She had studied English at the institute for nine months, which ended three months before the interview. Before that, she had been taking courses in different institutes intermittently between the ages of 10 to 17 . She had not travelled outside of Iran and had not experienced interactions in English.

Hanna (female) was 29 years old. She had studied English at the institute for a few months about four years ago, and she had started again about eight months before the study. She had also studied in other institutes between the ages of 13 to 18 continuously. She had travelled to China, Turkey, Dubai, and Russia and had experienced several intercultural interactions in English in Iran as well.

Leila (female) was 23 years old. She had started studying English at the institute about two years ago and continued for 15 months. Before that, since she was a child, she had been taking courses in different institutes intermittently. She had not travelled outside of Iran, but she had experienced several intercultural interactions in English with her sister's CouchSurfer guests. 